\title{
Contributions of ectomycorrhizal fungal mats to forest soil respiration
}

\author{
C. L. Phillips ${ }^{1,4}$, L. A. Kluber ${ }^{2,3}$, J. P. Martin ${ }^{3}$, B. A. Caldwell ${ }^{3}$, and B. J. Bond ${ }^{4}$ \\ ${ }^{1}$ Center for Accelerator Mass Spectrometry, Lawrence Livermore National Laboratory, Livermore, CA 94550, USA \\ ${ }^{2}$ Department of Biology, Case Western Reserve University, 2080 Adelbert Road, Cleveland, OH 44106, USA \\ ${ }^{3}$ Department of Crops and Soil Science, ALS 3017, Oregon State University, Corvallis, OR 97331, USA \\ ${ }^{4}$ Department of Forest Ecosystems and Society, Oregon State University, Corvallis, OR 97331, USA
}

Correspondence to: C. L. Phillips (claire.phillips@1lnl.gov)

Received: 18 January 2012 - Published in Biogeosciences Discuss.: 7 February 2012

Revised: 24 April 2012 - Accepted: 10 May 2012 - Published: 12 June 2012

\begin{abstract}
Distinct aggregations of fungal hyphae and rhizomorphs, or "mats", formed by some genera of ectomycorrhizal (EcM) fungi are common features of soils in coniferous forests of the Pacific Northwest. We measured in situ respiration rates of Piloderma mats and neighboring non-mat soils in an old-growth Douglas-fir forest in western Oregon to investigate whether there was higher respiration from mats, and to estimate mat contributions to total soil respiration. We found that areas where Piloderma mats colonized the organic horizon often had higher soil surface flux than nonmats, with the relative increase in respiration averaging $16 \%$ across two growing seasons. Both soil physical factors and biochemistry were related to the higher surface flux of mat soils. When soil moisture was high, soil $\mathrm{CO}_{2}$ production was concentrated into near-surface soil horizons where mats tend to colonize, resulting in greater apparent differences in respiration between mat and non-mat soils. Respiration rates were also correlated with the activity of chitin-degrading soil enzymes. This finding supports the notion that the abundance of fungal biomass in EcM mats is an important driver of $\mathrm{C}$ and $\mathrm{N}$ cycling. We found Piloderma mats present across $57 \%$ of the exposed soil, and use this value to estimate a respiratory contribution from mats at the stand-scale of about $9 \%$ of total soil respiration. The activity of EcM mats, which includes both EcM fungi and microbial associates, appeared to constitute a substantial portion of total soil respiration in this old-growth Douglas-fir forest.
\end{abstract}

\section{Introduction}

Soil respiration can have substantial influences on total forest carbon balance (Trumbore, 2006), and teasing apart component sources of soil respiration is an important step towards describing and predicting these fluxes. $\mathrm{CO}_{2}$ production by roots and soil microbes have been shown to differ from each other in timing and sensitivity to environmental variables (Carbone et al., 2008; Querejeta et al., 2003; Heinemeyer et al., 2007). The activity of EcM fungi, however, which are strictly speaking heterotrophic organisms but intimately dependent on plant carbon sources, does not fit neatly into plant or microbial categories. Mycorrhizal respiration is rarely quantified directly in the field, but is more often measured as a component of the pooled respiration from roots and their microbial associates, and called "rhizosphere", "autotrophic", or even "root" respiration (Tang and Baldocchi, 2005; Irvine et al., 2008; Carbone et al., 2008).

A potential opportunity to assess ectomycorrhizal (EcM) respiration is through examination of soils occupied by EcM mats. Mat-forming EcM fungi have a nearly global distribution (Castellano, 1988), and are common in coniferous forests of the Northwestern United States, where they form visible mats of rhizomorphs, or hyphal cords, in organic and mineral soil (Agerer, 2001, 2006; Trappe et al., 2012). EcM mats in the Douglas-fir forests of Western Oregon have been the subjects of a series of studies spanning thirty years, and have been shown to have distinct biological and chemical characteristics compared to adjacent soils without obvious mat development (non-mat soils). Mat characteristics include 
elevated levels of dissolved nitrogen and carbon, higher enzymatic activity, unique microbial communities, and elevated respiration rates in lab incubations (Griffiths et al., 1994; Griffiths and Caldwell, 1992; Kluber et al., 2010). Because EcM mats can be abundant, their high metabolic activity could contribute substantially to total forest soil respiration, especially in late seral stands (Griffiths et al., 1996; Dunham et al., 2007; Smith et al., 2000). In the present study, we employed a non-destructive approach to estimate mat respiratory contributions that compares soil surface $\mathrm{CO}_{2}$ efflux associated with mats to neighboring non-mat soils.

In some of the few other studies to estimate EcM respiratory contributions in situ, Heinemeyer et al. (2007, 2012a) installed mesh and solid partitions to exclude either roots or fungal mycelia from soil. In a study over a single growing season, they estimated as much as $25 \%$ of total soil respiration came from EcM hyphae in an early seral, lodgepole pine forest, and in a multi-year study in a deciduous oak system they estimated mycorrhizal fungi contributed $18 \%$ of total soil respiration. While physical exclosures greatly reduce the abundance of hyphae or roots, some trade-offs include the tendency to increase soil moisture, reduce labile soil carbon inputs, and the elimination of non-target genera such as saprotrophic fungi.

Investigating soil respiration rates of natural areas with and without EcM mats may provide a technique that complements other partitioning methods without severing connections to surrounding soil. Previous work indicates the presence or absence of mat-forming fungi has fewer confounding correlates than comparisons of bulk soil with hyphal exclosures. Rhizomorphic mats in the organic soil horizon have shown similar soil water content and root abundance as nonmat soils (Griffiths et al., 1990; Kluber et al., 2010). Recent molecular analyses of mat and non-mat soils also showed that non-mat soils are not devoid of fungi, but rather may be dominated by non-rhizomorphic fungi, including both EcM and saprotrophic fungi, that are less visible to the naked eye (Kluber et al., 2011).

Although non-mat soils do not strictly exclude EcM fungi, comparisons of mat and non-mat soils nevertheless contribute to a better understanding of respiratory contributions from EcM fungi by indicating how one particularly abundant EcM genus in the Northwestern USA, Piloderma, alters soil $\mathrm{CO}_{2}$ fluxes. Working in an old-growth forest (300-500 yr) at the HJ Andrews Experimental Forest in Oregon, USA, we sought to quantify differences in soil surface $\mathrm{CO}_{2}$ flux between mats in the Piloderma genus and non-mat soils. Piloderma has been shown to be the most common mat-forming EcM genus at HJ Andrews (Dunham et al., 2007), and its mats are easily recognized and delineated from non-mat soils by thick white or yellow rhizomorphs in the organic horizon.

Measuring respiration rates across two growing seasons, our primary research question was: (1) Is there an increase in soil surface $\mathrm{CO}_{2}$ flux from Piloderma mats compared with non-mat soil? In the event an increase could be detected, our secondary questions were: (2) How does the relative difference between mat and non-mat respiration vary seasonally with soil moisture and temperature? (3) Does the difference between mat and non-mat respiration relate to root biomass, soil physical properties, or soil enzyme activities? Finally, we sought to scale-up to the stand-level and inquire (4) what is the abundance of EcM mats across the stand, and what proportion of stand-level soil respiration does this equate to?

\section{Materials and methods}

\subsection{Site description}

The 0.1 ha study site was located at the HJ Andrews Experimental Forest, part of the Willamette National Forest, Oregon, USA $\left(44^{\circ} 13^{\prime \prime} 25^{\prime} \mathrm{N}, 122^{\circ} 15^{\prime \prime} 30^{\prime} \mathrm{W}, 484 \mathrm{~m}\right.$ above sea level). EcM mats are common at HJ Andrews, and we chose this site in part because it contained sufficient not-mat areas to provide contrasts with mat-colonized soils, and it has also been examined in previous studies (Dunham et al., 2007; Kluber et al., 2011; Griffiths et al., 1996). The forest was $\sim 450 \mathrm{yr}$ old, dominated by Douglas-fir (Psuedotsuga menziesii) and western hemlock (Tsuga heterophylla), both hosts for many EcM species, and western redcedar (Thuja plicata), a host for arbuscular mycorrhizal fungi, which do not form mats. Fallen logs in advanced stages of decay were common. The soil has strong andic properties and is classified as coarse loamy mixed mesic Typic Hapludands (Dixon, 2003), with an O-horizon depth of 4-9 cm.

This region experiences a Mediterranean (xeric) climate, with cool, moist winters and warm, dry summers. At this elevation snow accumulation is generally minimal; however, the winter during which the study was performed experienced record snow levels, with snow persisting from late December 2007-April 2008.

\subsection{Identification of fungal mats}

For the purposes of this study, mats were defined as dense profusions of rhizomorphs that aggregate humus or soil, are associated with obvious EcM root tips, and are uniform in structure and appearance for a depth of at least $2 \mathrm{~cm}$ and an area at least $12 \mathrm{~cm}$ in diameter. This definition is adapted from Dunham et al. (2007), who developed a criteria with input from Griffiths and Cromack to be consistent with earlier EcM mat studies (Cromack et al., 1979; Griffiths et al., 1990). Dunham et al. (2007) characterized the distribution of mat-forming EcM species in the organic and mineral soil horizons across the H. J. Andrews Experimental Forest, and showed that Piloderma (Basidiomycota; Agaricomycotina; Agaricomycetes; Agaricomycetidae; Atheliales; Atheliaceae) was the most common and widespread genus colonizing organic soils. Piloderma mats appear as stringy white or yellow rhizomorphs that permeate the organic soil horizon (Fig. 1). We initially identified 


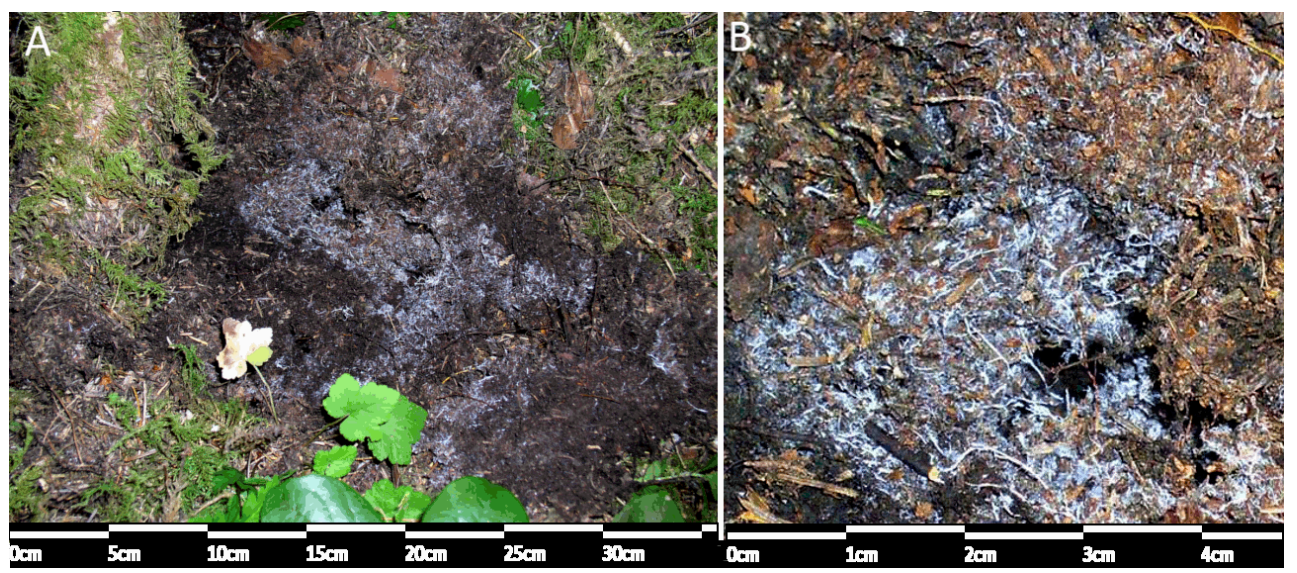

Fig. 1. Photograph of a Piloderma mat (A) Piloderma mat colonizing the O-horizon, (B) close-up of rhizomorphic growth habit. Size scales shown are approximate.

mats as Piloderma-like visually in the field, and later confirmed their identity using molecular approaches (described below).

Mat and non-mat areas were identified by conducting an initial survey of the site in July 2006. We randomly choose $501 \times 1$ m quadrats to quantify mat percent cover. We peeled back the bryophyte layer to expose the organic horzion to search for Piloderma mats, and then gently lifted the organic layer to look for other mat genera that colonize the mineral-organic soil interface. We determined our site had a very low occurrence of mats at the mineral soil interface (Table 1), therefore we focused our subsequent work only on Piloderma-like mats and non-mat areas. We estimated the area occupied by each mat by multiplying the average width and length from 3 to 5 measurements in each major axis. We also quantified the area occupied by large roots or downed $\operatorname{logs}$ that prevented colonization of the organic horizon, and where soil surface flux could not be characterized. We report two values for mat cover: the percentage of exposed soil available to be colonized by mats, and the percentage of the entire surveyed area.

We identified 21 areas that were suitable for paired respiration measurements, containing dense mats adjacent to distinctly non-rhizomorphic soil ( $\leq 1 \mathrm{~m}$ apart). To minimize potential rhizomorph colonization in non-mat areas over the course of the experiment, or recession of rhizomorphs in mat areas, we also required that both mats and non-mats had to be at least $15 \mathrm{~cm}$ in diameter. Twelve of these candidate pairs were randomly selected for long-term respiration measurements.

To confirm that the mats used in this study were indeed formed byPiloderma, we used terminal restriction fragment lengthpolymorphism (T-RFLP) analysis as described by Kluber et al. (2011). This method has been shown to be robust and reliable because the T RFLP profiles of Piloderma mats are distinct and dominated by a characteristic Piloderma frag- ment (Kluber et al., 2011). A small amount of soil $(\sim 10 \mathrm{~g})$ was sampled in June 2008 adjacent to each respiration measurement area, and the entire respiration measurement area $(\sim 100 \mathrm{~g})$ was resampled again at the completion of respiration measurements to assess whether Piloderma persisted as the dominant phylotype over time.

\subsection{Soil respiration measurements}

Soil surface $\mathrm{CO}_{2}$ efflux rates were measured with a portable gas exchange system and soil efflux chamber (Li-Cor model 6400 and 6400-19, respectively, LI-COR Biosciences, Lincoln, NE, USA). To provide an interface between the soil and the respiration chamber, collars were constructed from opaque PVC pipe $(7.7 \mathrm{~cm}$ inner diameter, $0.5 \mathrm{~cm}$ wall thickness, $5 \mathrm{~cm}$ height, $90.3 \mathrm{~cm}^{2}$ soil surface area) and were pushed $\sim 1 \mathrm{~cm}$ into the organic horizon. Any potential severing of roots or hyphae appeared to be minimal because the thick soil humus tended to compress under the collar rims. Soil collars were installed $48 \mathrm{~h}$ prior to initial measurements and left in place for the duration of the study. Bryophytes and small green plants growing inside the collars were removed, and a plug of unrooted bryophytes was replaced in the collar between measurement dates to mimic surrounding ground cover.

To check that mat soils remained rhizomorphic and nonmat soils did not become rhizomorphic over the course of the study, we probed the O-horizon adjacent to soil collars approximately every 2 months to detect changes in rhizomorph density.

\subsection{Seasonal variation in EcM mat contributions}

Soil temperature and moisture were measured concurrently with respiration measurements and analyzed as potential seasonal drivers of mat respiration. Temperature at $10 \mathrm{~cm}$ depth was measured by inserting a steel probe surrounding a Type 
Table 1. Percent of soil surface occupied by: coarse plant material (which prevented mat colonization), mats at the mineral-soil surface, Piloderma-like fungal mats in the organic horizon, and non-mat soil.

\begin{tabular}{lcccc}
\hline & Tree boles, roots, and CWD & \multicolumn{2}{c}{ EcM Mats } & \multirow{2}{*}{ Non-mat } \\
\cline { 2 - 4 } & & $1.9 \%$ & $42.2 \%$ & $33.2 \%$ \\
& $22.8 \%$ & Mineral-soil surface & Piloderma-like \\
\hline Total area & - & $2.6 \%$ & $56.6 \%$ & $40.9 \%$ \\
Exposed soil & - & & \\
\hline
\end{tabular}

E thermocouple (Omega Engineering, Stamford, CT, USA) adjacent to the respiration collars. We measured gravimetric water content in the $\mathrm{O}$-horizon, and at 5 and $15 \mathrm{~cm}$ below the mineral soil surface, by collecting soil cores from five small coring fields established across the study area and associating each soil collar with moisture values from the nearest coring field.

To better understand how moisture variability may effect soil surface flux rates, we also established instrumented soil profiles in two area - one mat-dominated and one non-matdominated - to calculate the relative contributions of subsurface horizons to surface flux (Fig. 2). Previous work has shown the contributions of the O-horizon can vary seasonally with soil moisture (Davidson et al., 2006), which implies that surface flux measurements may not be equally sensitive to differences between mat and non-mat activity throughout the year. We anticipated that as soils dried down, surface fluxes would originate from deeper, wetter soils, and that relative contributions from the O-horizon would decrease. To test this, we vertically partitioned $\mathrm{CO}_{2}$ production at our site following the approach of Davidson et al. (2006), in which $\mathrm{CO}_{2}$ fluxes derived from each soil horizon are modeled according to Fick's first law of diffusion:

$F=D_{\mathrm{S}} \frac{\mathrm{d} C}{\mathrm{~d} z}$,

where $F$ is $\mathrm{CO}_{2}$ efflux $\left(\mathrm{mmol} \mathrm{m}^{-2} \mathrm{~s}^{-1}\right), D_{\mathrm{S}}$ is the effective $\mathrm{CO}_{2}$ diffusivity in soil $\left(\mathrm{m}^{2} \mathrm{~s}^{-1}\right), C$ is $\mathrm{CO}_{2}$ mole concentration, and $z$ is depth. We calculated fluxes approximately every 2 months during the growing season, based on $\mathrm{CO}_{2}$ concentrations collected from $30 \mathrm{ml}$ gas wells that we drilled into the interfaces between genetic soil horizons from a hand-dug trench. Two sets of wells were installed at opposite ends of each area to better capture spatial variability. Measurements from both profiles were combined in a scatter plot and fit with a third-order polynomial to estimate $\mathrm{d} C / \mathrm{d} z$ at each horizon interface. We estimated $D_{\mathrm{S}}$ as described by Moldrup et al. (1999), using soil temperature and volumetric water content measurements from probes buried at each depth (temperature with Type-T thermocouple, Omega Corp, and moisture with CS-615 TDR probe, Campbell Scientific, Logan, Utah, USA).

$\mathrm{CO}_{2}$ samples were collected into $12 \mathrm{ml}$ Exetainer ${ }^{\mathrm{TM}}$ vials (Labco, UK), which were pre-flushed with $\mathrm{N}_{2}$ and evacuated in the field with a hand pump. $\mathrm{CO}_{2}$ samples were analyzed

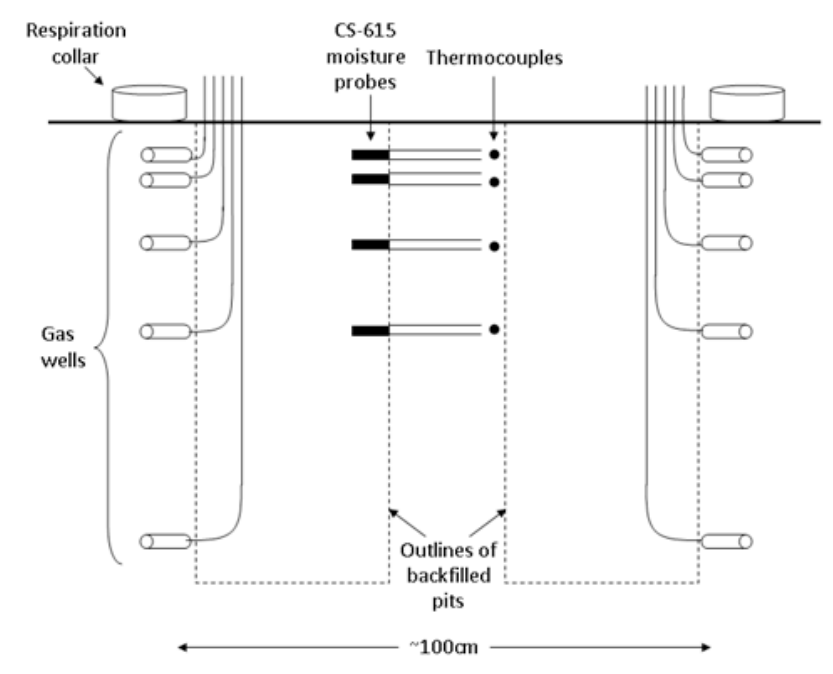

Fig. 2. Schematic of instrumentation used for vertically partitioning soil $\mathrm{CO}_{2}$ production.

within $48 \mathrm{~h}$ in the laboratory using a LiCor-6252 infrared gas analyzer (LI-COR Biosciences, Lincoln, NE, USA) configured for injection of small volumes (Davidson and Trumbore, 1995). A calibration curve was created by injecting standard gases to translate peak height to $\mathrm{CO}_{2}$ concentration. The combined standard uncertainties of the measurements, which include sampling and instrument uncertainties (NIST guidelines, Taylor and Kuyatt, 1994), were determined based on replicate analyses to be $3.8 \%$ of $\mathrm{CO}_{2}$ concentration.

We quantified production in each horizon as the difference between fluxes leaving the top and entering the bottom of each horizon. For the O-horizon, production was estimated as the difference between average surface efflux from the two collars in each area, and the incoming flux from the Ahorizon. Production from the C-horizon and below was estimated as the flux of $\mathrm{CO}_{2}$ from the top of the C-horizon. Monte Carlo simulations were performed to propagate uncertainties for component measurements and to calculate overall uncertainties for production from each horizon. The uncertainties of measured data were determined when possible from the standard deviation of repeated measures. For nonreplicated measures ( $\% \mathrm{OM}$ and soil texture), uncertainty was assumed to be $5 \%$, and for bulk density we used a conservative uncertainty estimate of $10 \%$. 


\subsection{Spatial drivers of mat and non-mat respiration}

We conducted a number of analyses to assess potential factors influencing spatial variation in soil surface flux. In addition to the twelve long-term measurement locations described above, at the outset of the study we randomly chose an additional 9 Piloderma mat and 5 non-mat soils for one time destructive sampling. After measuring surface $\mathrm{CO}_{2}$ efflux at each location, we removed cores $8 \mathrm{~cm}$ in diameter to measure root biomass, $\% \mathrm{C}$ and $\% \mathrm{~N}$, soil $\mathrm{pH}$, moisture, and litter depth. Soil cores were separated into 4 depth increments: the entire O-horizon, $0-10 \mathrm{~cm}, 10-20 \mathrm{~cm}$, and 20$35 \mathrm{~cm}$ below the mineral soil surface. Fine root $(<2 \mathrm{~mm}$ diameter) and total root biomass were determined by wet sieving soils, picking roots by hand, and measuring dry weight of both live and dead roots. Roots were also combusted and weights were corrected for non-combustible material (adhered soil). We measured total soil $\mathrm{C}$ and $\mathrm{N}$ by drying $1 \mathrm{~g}$ of organic soil and $5 \mathrm{~g}$ of mineral soil at $65^{\circ} \mathrm{C}$ for $48 \mathrm{~h}$, grinding soils to fine powder on a roller mill, and analyzing $3-10 \mathrm{mg}$ subsamples on a Costech ECS-4010 elemental combustion analyzer (Costech Analytical, Valencia, CA, USA) against an atropine standard.

At the completion of the study in November 2008, we also destructively harvested the long-term respiration measurement locations and analyzed the activity of chitin-degrading enzyme, N-acetyl-b-D-glucosaminidase (chitinase or NAGase), as described by Kluber et al. (2010). We chose to focus on this enzyme because a survey of EcM mat enzyme activity across the HJ Andrews Experimental Forest showed that chitinase was the only enzyme to differ significantly between Piloderma mats and non-mat soils (Kluber et al., 2010). Chitinase has also been shown by others to correlate strongly with independent measures of fungal biomass (Miller et al., 1998). Here we examined whether chitinase activity correlated with soil surface $\mathrm{CO}_{2}$ flux rate.

\subsection{Data analysis}

We tested whether the difference between neighboring mat and non-mat pairs was different from zero in each year of the study using a linear mixed effects model, with pair location as a random effect, and a linear correlation matrix to accommodate unequal sampling intervals over time (Pinheiro and Bates, 2000). Results from 2006 and 2007 were analyzed independently due to large differences in moisture conditions and in respiration magnitude and variance.

To examine correlations between mat respiration and moisture and temperature, we started with a commonly-used model to describe respiration as an exponential function of temperature and moisture (Martin and Bolstad, 2005) Sulzman et al. (2005):
$F=\alpha e^{\beta_{1} T+\beta_{2} M}$

where $F$ is surface flux, $T$ is soil temperature, and $M$ is soil moisture. To estimate parameters for this model with linear regression techniques, we took the natural logarithm of each side

$\ln F=\ln \alpha+\beta_{1} T+\beta_{2} M$

and calculated the difference between neighboring mat $\left(F_{\mathrm{m}}\right)$ and non-mat soils $\left(F_{\mathrm{nm}}\right)$ as follows:

$\ln F_{\mathrm{m}}-\ln F_{\mathrm{nm}}=\ln \left(\frac{F_{\mathrm{m}}}{F_{\mathrm{nm}}}\right)=\ln R_{\mathrm{m}}$,

where $R_{\mathrm{m}}$ is the ratio of mat and non-mat fluxes.

The impacts of temperature and moisture on $R_{\mathrm{m}}$ were assessed by estimating coefficients for the following model:

$\ln R_{\mathrm{m}}=\ln \alpha+\beta_{1} T_{\mathrm{ave}}+\beta_{2} M_{\mathrm{ave}}$,

where $T_{\text {ave }}$ is the average temperature for each mat and nonmat pair, and $M_{\text {ave }}$ is the O-horizon gravimetric water content. We solved for coefficients in Eq. (5) using a statistical linear mixed effects model, with temperature and moisture as fixed effects, pair location as a random effect, and a linear correlation matrix for the variance-covariance structure to account for repeated measures.

For ease of interpretation we report the relative difference between mat and non-mat soils as a percent difference, where

mat relative difference $=\left(R_{\mathrm{m}}-1\right) \times 100$.

We also examined whether any of the soil properties from destructively-harvest cores correlated with respiration rates by analyzing individual linear regressions for each soil property. All analyses were performed with S-PLUS v.8.

\section{Results}

\subsection{Differences between mat and non-mat respiration}

Visual checks of rhizomorph abundance indicated most mat and non-mat soils remained stable over the course of the study; however, in the second growing season, we omitted three pairs in which the mat soil became too weakly rhizomorphic to be considered mats, and two pairs in which the non-mat soils became colonized. Thus, only seven of the original 12 pairs were analyzed in summer 2008. We only included date ranges for each pair where we had positive visual confirmation of the soil conditions.

The difference in respiration between neighboring mat and non-mat pairs was greater than zero on most, but not all, sampling dates (Fig. 3). Surface flux from Piloderma mats 

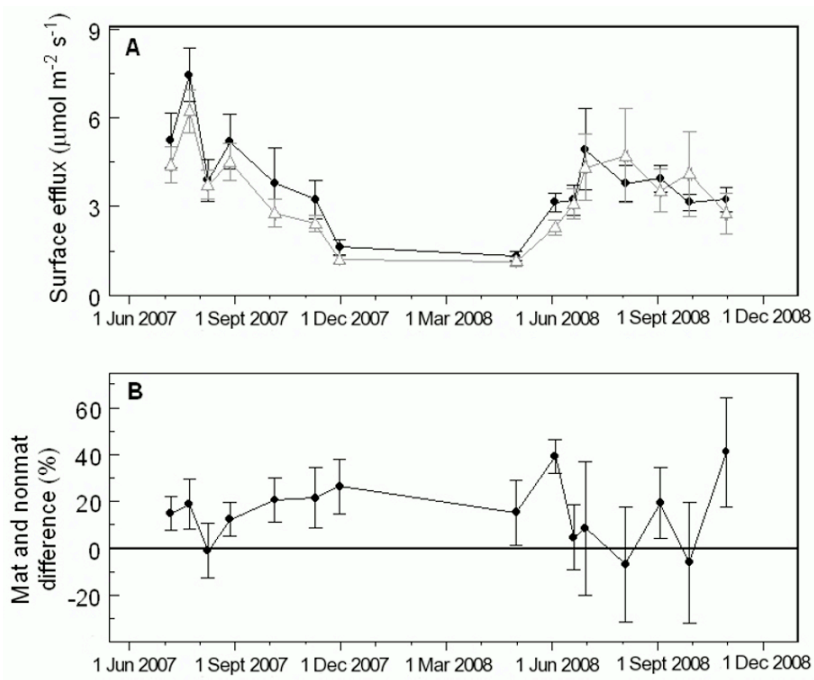

Fig. 3. Time series of soil respiration and calculated mat contributions. (A) Average respiration from mat (O) and non-mat soils $(\triangle)$. (B) Percent difference between mat and neighboring non-mat surface efflux. Error bars are standard error $(N=12$ in 2007,7 in 2008).

averaged $17 \%$ higher than non-mat soil during the first growing season $(95 \% \mathrm{CI}=10-25 \%)$, and $16 \%$ higher in the second growing season $(95 \% \mathrm{CI}=7-27 \%)$. However, the difference between mat and non-mat respiration was especially variable in the second year of the study. In early June 2008, there was a notable high, but brief, spike in the difference between mat and non-mat respiration, with mat surface flux averaging almost $40 \%$ higher than non-mat surface flux. When we sampled again only two weeks later, mat respiration was not statistically different from non-mat respiration and the difference remained low throughout the summer. The difference between mat and non-mat respiration increased quite high again following fall rewetting in November 2008, but with greater spatial variability than previous sampling dates.

\subsection{Seasonal variation}

While raw surface $\mathrm{CO}_{2}$ efflux rates from both mat and nonmat soils correlated strongly with soil temperature, multiple regression indicated temperature was not a significant predictor of the difference between mat and non-mat respiration $(P=0.5)$. O-horizon soil moisture, however, was a significant predictor $(P<0.001)$, and for every $10 \%$ increase in moisture, the relative difference between mat and non-mat respiration increased by $8 \%(95 \% \mathrm{CI}=3.6-13.9 \%)$. Although temperature and moisture effects were analyzed in a single model, the individual effects of temperature and moisture, respectively, are shown in Figs. 5 and 6.

Vertical partitioning of soil $\mathrm{CO}_{2}$ production also suggested soil moisture impacted the relative contributions of surficial and deep soil horizons (Fig. 7). From analyses of $\mathrm{CO}_{2}$ pro-
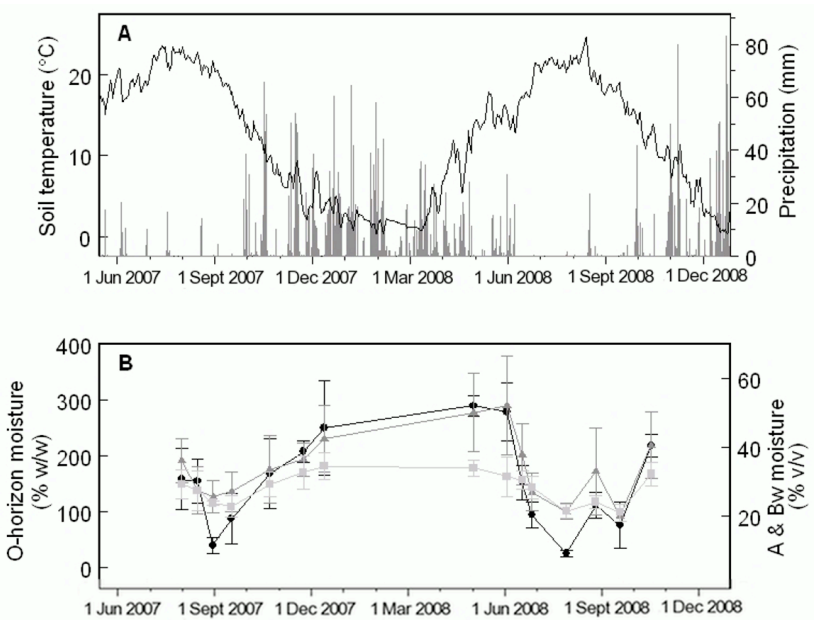

Fig. 4. Time series of precipitation, soil moisture, and soil temperature. (A) Soil temperature at $10 \mathrm{~cm}$ depth (black line) and precipitation (grey lines) from the H. J. Andrews headquarters weather station (430 $\mathrm{m}$ above sea level). (B) Soil moisture sampled at study site. O-horizon gravimetric water content $(\mathbf{O})$, and volumetric water content at $5 \mathrm{~cm}(\triangle)$ and $15 \mathrm{~cm}(\boldsymbol{\square})$ below mineral soil surface (gravimetric water content $\times$ bulk density). Error bars are standard deviation, $N=5$.

files in mat and non-mat areas of the study site, the estimated contributions from the $\mathrm{O}$ horizon averaged $73 \%$ of total surface flux $(95 \% \mathrm{CI}=61-85 \%)$, but ranged from as much as $93 \%$ in May when snow had just melted and the ground was essentially saturated, to $37 \%$ in August when the soil was extremely dry (4-6\% water content at the O/A interface). $\mathrm{CO}_{2}$ contributions from the A horizon were small and often indistinguishable from zero when calculated with this approach. We even calculated a $\mathrm{CO}_{2}$ sink in the A-horizon in early October of both years when the $\mathrm{O}$ horizon had regained more moisture than the underlying mineral soil, potentially preventing diffusive losses from the A horizon. The errors associated with these negative production values were large, however, due to variable $\mathrm{CO}_{2}$ concentrations and inherent uncertainties in estimating soil $\mathrm{CO}_{2}$ diffusivity.

Overall, the vertical partitioning results indicate that when soils were moist, the majority of surface efflux originated from shallow depths where Piloderma colonizes, with only minor contributions from sub-mat deeper soil. The two sampling days that occurred during dry conditions in the late summer, however, showed sources of $\mathrm{CO}_{2}$ shifting to deeper soil horizons (see August 2007 and July 2008 in Fig. 7). Correlations between $\mathrm{CO}_{2}$ production and soil moisture measured in each horizon (Fig. 8) showed no relationship for surficial $\mathrm{O}$ and $\mathrm{A}$ horizons, but indicated that the $\mathrm{B}$ and $\mathrm{C}$ horizons tended to increase $\mathrm{CO}_{2}$ production as they dried. This suggests that high moisture in the spring and fall may increase $\mathrm{CO}_{2}$ storage or suppress aerobic respiration in deep soil layers. As deep soil layers dry through the summer and 


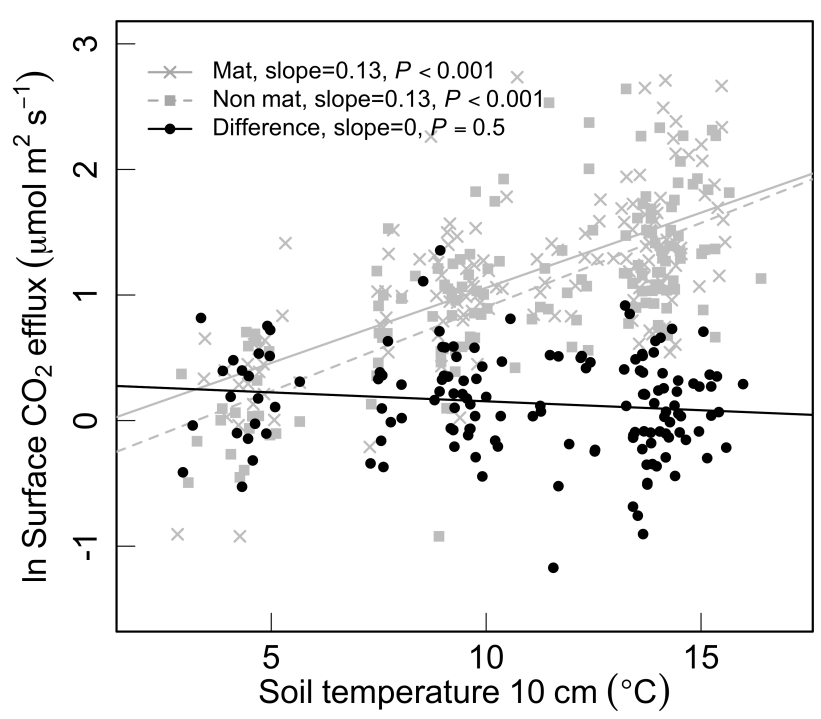

Fig. 5. Relationship between soil temperature and soil surface efflux. Surface efflux rates for mat and non-mat soils, are shown lntransformed, corresponding to the model in Eq. (3). The difference between these values, also equivalent to $\ln \left(F_{\mathrm{M}} / F_{\mathrm{NM}}\right)$ corresponds to the model in Eq. (5). Regression slopes and $P$-values shown here are for the temperature coefficients extracted from mixed effects analyses.

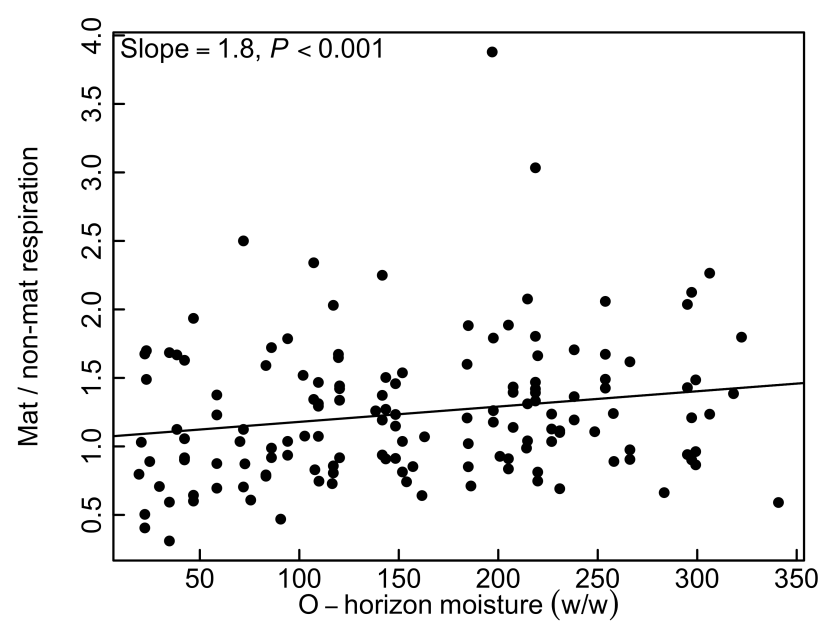

Fig. 6. Relationship between the ratio of mat to non-mat surface efflux, and O-horizon soil moisture. The slope and $P$-value are for the moisture coefficient estimated for the model in Eq. (5), shown here on a non-logarithmic scale.

contribute relatively more $\mathrm{CO}_{2}$, the dilution of surficial soil fluxes may make it more difficult to detect difference between mat and non-mat areas.

\subsection{Spatial variation}

From cores sampled at the outset of the study, we found no significant individual correlations between respiration rate

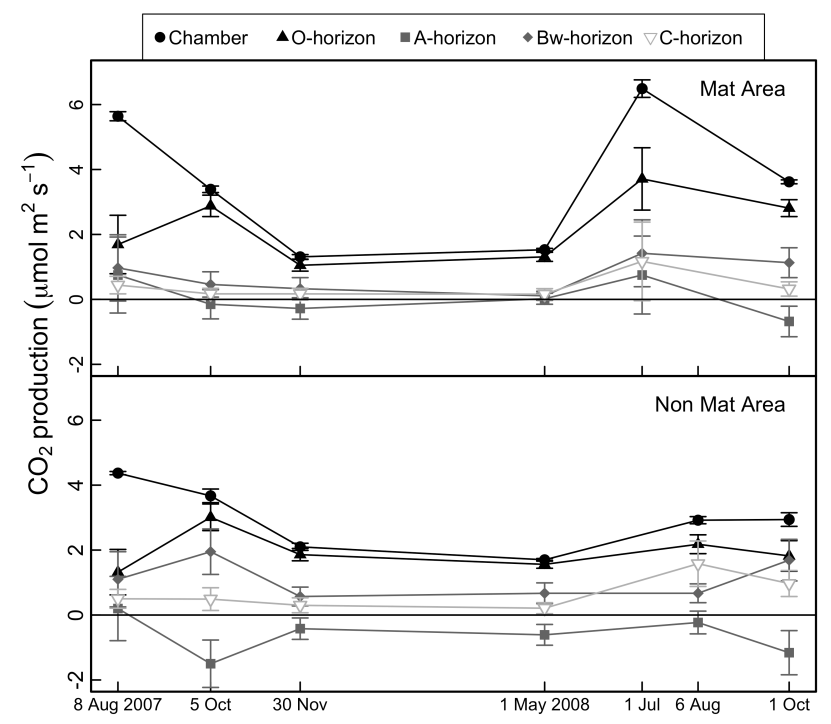

Fig. 7. Vertical partitioning of soil respiration over time. Measured surface $\mathrm{CO}_{2}$ flux and calculated $\mathrm{CO}_{2}$ production in the $\mathrm{O}, \mathrm{A}, \mathrm{Bw} 1$ $+\mathrm{Bw} 2$, and $\mathrm{C}$ horizons. Duplicate $\mathrm{CO}_{2}$ profiles and surface flux rates were combined for each area. Error bars represent the propagated uncertainty from Monte Carlo simulations (see methods for details).

and soil moisture, fine root biomass, total root biomass, $\% \mathrm{C}$, $\% \mathrm{~N}, \mathrm{C}: \mathrm{N}$ ratio, or litter depth (Table 2). Furthermore, none of the soil characteristics, including respiration, differed significantly between mat and non-mat soils for this set of nonpaired soil locations. These results have important implications for the validity of our approach to estimate mat respiratory contributions. Based on these soil samples, we have no evidence that soil physical properties, $\mathrm{C}$ or $\mathrm{N}$ abundance, or root abundance vary systematically between mat and nonmat areas, or that they could have biased respiration rates.

We also found a significant correlation between respiration rate and NAGase activity, measured from paired mat and non-mat cores collected at the end of the study (Fig. 9). Chitinase activity explained $66 \%$ of the variance in soil surface respiration. Chitinase activity of mats was about $40 \%$ higher than neighboring non-mat soils, though the difference was not significant at the $P=0.05$ level $(1.23$ vs. $0.77 \mathrm{mmol}$ substrate $\mathrm{h}^{-1}$, one-tailed $P=0.055$ for paired t-test).

\subsection{Upscaling of EcM mat cover and respiration}

Surveys of the 0.1 ha study area revealed almost half of the forest floor contained EcM mats (Table 1). Piloderma-like mats occupied approximately $42 \%$ of the total areal extent of forest floor, and mats at the mineral-soil surface that resembled Ramaria (hydrophobic, ash-like, grey) occupied another $1.9 \%$. Trees, coarse roots, and coarse woody debris also covered about $23 \%$ of the soil surface. Excluding these areas that prevented mat colonization in the $\mathrm{O}$ horizon, almost 


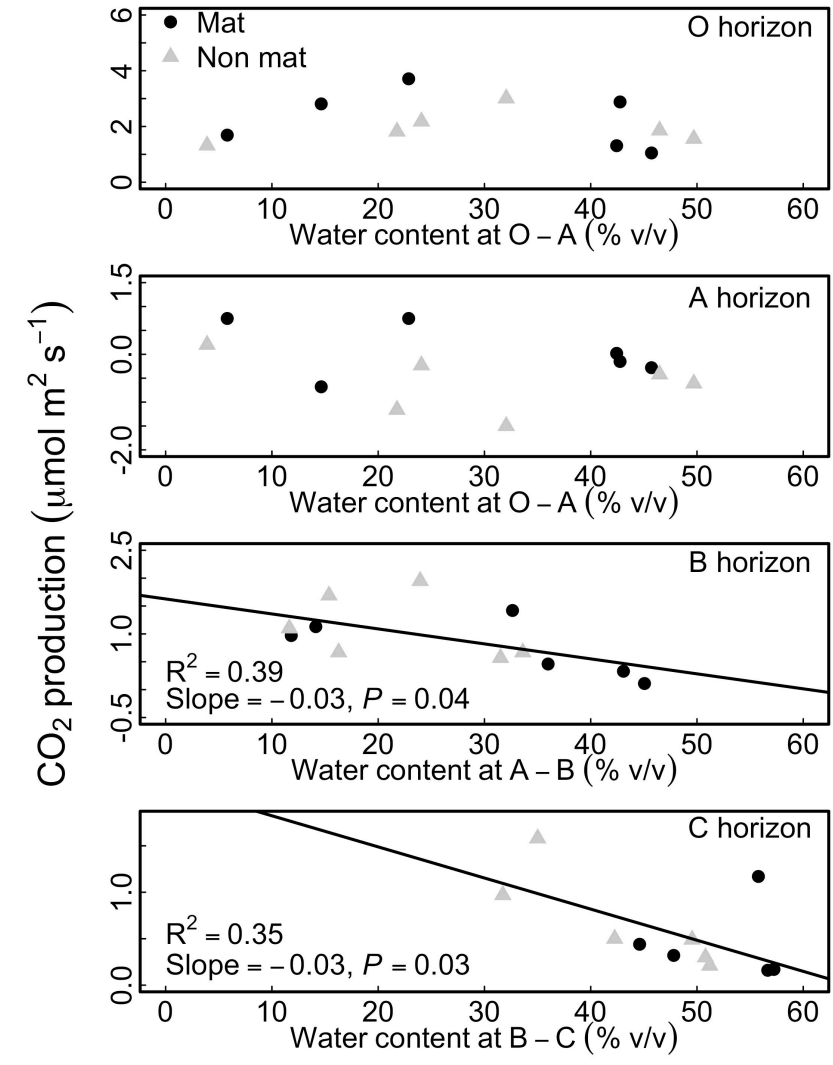

Fig. 8. Effect of soil moisture on production from each genetic soil horizon (same production data as shown in Fig. 7). Water content was measured at the bottom of the O-horizon (top panel), and at the top of the other genetic soil horizons.

$57 \%$ of the accessible soil surface was occupied by Piloderma-like mats, and $2.6 \%$ was occupied by mats at the mineral soil surface.

Since it was not possible to obtain direct measurements of soil respiration from areas occupied by trees, large roots, or coarse woody debris, and we cannot assume these areas have soil respiration rates similar to non-mat soil, we estimated respiratory contributions from Piloderma mats for the accessible soil surface that we were able to characterize. We multiplied the percent cover of Piloderma mats across the accessible soil surface $(56.6 \%)$ by the average relative difference between mat and non-mat areas $(17 \%$ in 2007 and $16 \%$ in 2008). Thus, excluding areas with trees, large roots, or woody debris, we estimated that Piloderma mats contributed $9.6 \%$ of soil respiration in the first, wetter, year $(95 \% \mathrm{CI}=10-14 \%)$ and $9.1 \%$ in the second, drier, year $(95 \% \mathrm{CI}=4-15 \%)$.

\section{Discussion}

\subsection{Seasonal patterns of mat and non-mat respiration}

We found generally higher surface $\mathrm{CO}_{2}$ efflux from mat soils compared to neighboring non-mat soils, with an average relative difference of about $16 \%$ across the 2007 and 2008 growing seasons. The in situ differences between mat and non-mat respiration measured here, although substantial, were much smaller than differences measured in previous lab incubation studies. Griffiths et al. (1990) sampled rhizomorphic mat and non-mat soil cores monthly over two years and consistently found respiration rates three to 11 times higher in mat soils, although these large differences may have resulted in part from disturbance and severing of fungal hyphae. In addition, we likely detected a smaller difference between mat and non-mats soils because in situ efflux measurements include $\mathrm{CO}_{2}$ contributions from deeper horizons devoid of Piloderma mats, which could mute differences within the organic horizon.

Seasonal variations in the difference between mat and nonmat respiration corresponded with soil moisture, but not with temperature. Heinemeyer et al. (2007, 2012a) arrived at a similar conclusion in both of their field studies of EcM hyphal respiration, finding that the difference in respiration rate between mesh exclosures containing EcM hyphae and solid exclosures containing no EcM hyphae corresponded with soil moisture but not temperature. In lab incubations of soil cores collected through time, however, Griffiths et al. (1991) found no relationship between soil moisture and relative differences between mat and non-mat respiration. This discrepancy, which indicates the importance of field studies, suggests different drivers may be apparent under laboratory and field conditions.

\subsection{Vertical partitioning of $\mathrm{CO}_{2}$ sources}

Our estimates of vertical partitioning highlight the potential for soil physical processes to alter the depth from which surface $\mathrm{CO}_{2}$ efflux originates. Although most $\mathrm{CO}_{2}$ production was estimated to occur within the organic horizon, the contributions of $\mathrm{CO}_{2}$ from deep soil horizons changed over time and proportionally increased on dry sampling days. Because Piloderma mats only occur in the $\mathrm{O}$ horizon, we suspect that mat and non-mat areas had more similar respiration rates during dry periods in part because the relative $\mathrm{CO}_{2}$ contributions from deeper horizons increased. This explanation does not exclude, however, other biological factors that could also affect the moisture sensitivity of EcM mat contributions. For instance, tree hosts experiencing decreased leaf conductance and carbohydrate supply may reduce carbon translocation to EcM associates under dry conditions.

It is important to acknowledge large uncertainties inherent in these partitioning calculations. We have used Monte Carlo simulations to propagate sources of error through component 
Table 2. Average characteristics for mat $(n=9)$ and non-mat $(n=5)$ soils cored 7 July 2007. No significant differences were found between mat and non-mat soils, and none of the variables in the organic horizon or $0-10 \mathrm{~cm}$ mineral soil correlated with surface $\mathrm{CO}_{2}$ efflux.

\begin{tabular}{|c|c|c|c|c|c|c|}
\hline \multirow[t]{3}{*}{ Soil Characteristics } & \multicolumn{2}{|c|}{ Mat } & \multicolumn{2}{|c|}{ Non-mat } & \multirow[t]{2}{*}{$t$-test } & \multirow{2}{*}{$\begin{array}{r}\text { Correlation with } \\
\mathrm{CO}_{2} \text { efflux }\end{array}$} \\
\hline & \multicolumn{4}{|c|}{ O-horizon } & & \\
\hline & avg & std dev & avg & std dev & $p^{1}$ & $p^{2}$ \\
\hline surface $\mathrm{CO}_{2}$ efflux $\left(\mu \mathrm{mol} \mathrm{m} \mathrm{m}^{-2} \mathrm{~s}^{-1}\right)$ & 5.14 & $(1.89)$ & 5.79 & $(3.89)$ & 0.74 & - \\
\hline O-horizon depth $(\mathrm{cm})$ & 9.1 & $(4.9)$ & 5.9 & $(4.7)$ & 0.27 & 0.62 \\
\hline $\mathrm{pH}$ & 4.80 & $(0.46)$ & 5.48 & $(0.78)$ & 0.13 & 0.19 \\
\hline moisture (w/w) & 1.15 & $(0.34)$ & 0.92 & $(0.33)$ & 0.29 & 0.36 \\
\hline$\% \mathrm{C}$ & 39.90 & $(9.79)$ & 37.39 & $(8.78)$ & 0.63 & 0.77 \\
\hline$\% \mathrm{~N}$ & 0.96 & $(0.24)$ & 1.17 & $(0.47)$ & 0.38 & 0.28 \\
\hline $\mathrm{C}: \mathrm{N}$ & 42.37 & (9.87) & 35.69 & (14.71) & 0.40 & 0.80 \\
\hline fine roots $(\mathrm{g})$ & 1.71 & $(0.92)$ & 1.03 & $(0.75)$ & 0.17 & 0.42 \\
\hline \multirow[t]{2}{*}{ total roots $(\mathrm{g})$} & 2.75 & $(1.95)$ & 3.4 & $(5.66)$ & 0.81 & 0.72 \\
\hline & \multicolumn{6}{|c|}{$0-10 \mathrm{~cm}$ mineral soil } \\
\hline $\mathrm{pH}$ & 4.77 & $(0.43)$ & 5.03 & $(0.89)$ & 0.56 & 0.26 \\
\hline moisture (w/w) & 0.53 & $(0.22)$ & 0.53 & $(0.22)$ & 0.96 & 0.57 \\
\hline$\% \mathrm{C}$ & 9.88 & $(7.60)$ & 9.85 & (9.24) & 1.00 & 0.82 \\
\hline$\% \mathrm{~N}$ & 0.23 & $(0.10)$ & 0.24 & $(0.13)$ & 0.83 & 0.79 \\
\hline $\mathrm{C}: \mathrm{N}$ & 39.43 & $(12.37)$ & 33.54 & (18.87) & 0.55 & 0.74 \\
\hline fine roots $(\mathrm{g})$ & 1.16 & $(0.46)$ & 1.02 & $(0.31)$ & 0.51 & 0.27 \\
\hline total roots $(\mathrm{g})$ & 2.71 & $(2.34)$ & 1.48 & $(0.47)$ & 0.16 & 0.40 \\
\hline
\end{tabular}

${ }^{1}$ Two-sided test for difference between mat and non-mat soils.

2 One-sided test for Pearson's correlation coefficient greater than zero.

calculations, but the assumption of steady-state diffusion and the fact that we used a combination of modeling and direct measurements to estimate production from the $\mathrm{O}$ horizon introduce uncertainties that are difficult to quantify. Considering these limitations, the vertical partitioning estimates are most useful in a qualitative sense, as an indicator of how subsurface $\mathrm{CO}_{2}$ production may change relatively through time with movement of wetting and drying fronts. For instance, it seems likely that this approach systematically underestimated production from the A horizon, but may have captured the temporal dynamics of A horizon contributions, including a relative decrease during fall rewetting and a relative increase during late summer drought. In the future, new techniques that use membranes to impose a known diffusive regime may provide a better means for measuring subsurface $\mathrm{CO}_{2}$ fluxes (Risk et al., 2011; Heinemeyer et al., 2012b).

In this study, dry soil conditions were associated with lower respiratory contributions from EcM mats; however, the impacts of drying fronts may differ in other systems. While Piloderma represents an EcM species with preference for organic soil, respiration sources may differ in other systems, depending on rooting and microbial profiles. The absolute abundance of EcM fungi is often greatest in surificial soil horizons (Erland and Taylor, 2002), but the relative activity of EcM fungi compared to other microbes can be proportionally lower in surficial horizons and increase with depth
(Lindahl et al., 2007). In general, it would help to improve conceptual models of soil respiration if more researchers assessed the interactions between drying fronts and respiratory contributions from different biota.

\subsection{Spatial patterns in mat and non-mat respiration}

An important assumption of our approach for quantifying respiration from Piloderma mats is that mat and non-mat areas do not have systematic differences in soil properties that could confound comparisons of respiration rate. Our spatial sampling campaign was performed to test this assumption. Across the site, we found no significant differences $\% \mathrm{C}$, $\% \mathrm{~N}$, litter depth, or soil moisture between mat and non-mat areas from cores taken to $35 \mathrm{~cm}$ depth, nor did surface $\mathrm{CO}_{2}$ efflux rate correlate with any of the variables. We also found root biomass was similar in mat and non-mat soils, consistent with previous EcM mat studies (Griffiths et al., 1990). For these non-adjacent mat and non-mat core analyzed at the outset of the study, however, we also found no significant differences in surface $\mathrm{CO}_{2}$ efflux rate. It appears necessary to compare soils in close proximity to each other to detect respiration differences between soil types.

Across the paired, long-term measurement locations, we found a trend $(P=0.55)$ towards higher chitinase activities in mat soils than non-mats, and a significant correlation 
between respiration rate and chitinase activity across both soil types. Because chitinase activity can correlate with fungal abundance (Miller et al., 1998), the correlation between chitinase and respiration may indirectly indicate a linkage between respiration and fungal abundance. Although we did not examine activities of other enzymes, previous work in this system showed that chitinase activity differed strongly between Piloderma mats and non-mat soils, whereas other enzyme activities (including phenoloxidase, $\beta$-glucosidase, phosphatase, and protease) did not differ between soil types (Kluber et al., 2010).

Chitinase activity in mat soils may be related not only to fungal activity, but also to activity of associated bacteria. Mat-forming EcM fungi not only share close metabolic associations with tree hosts, but also harbor distinct bacterial and fungal communities that could influence enzyme activities (Kluber et al., 2010) as well as respiration rates. There is also evidence to suggest fungal tissue itself may be a quantitatively important source of $\mathrm{C}$ and $\mathrm{N}$, in the form of chitin and its monomeric building block $\mathrm{N}$-acetyl glucosamine (NAG, Zeglin et al., 2012). EcM fungi have been shown previously to produce NAGase to recycle chitin-N (Aerts, 2002), and other soil microbes may produce NAGase to advantageously utilize chitin (Miller et al., 1998).

Although we did not identify significant differences in other soil properties between mat and non-mat locations, Piloderma mats undoubtedly are distributed non-randomly with preference for certain environments. For instance, Griffiths et al. (1996) found rhizomorphic EcM mats occurred more commonly near the base of potential tree hosts as well as clustered near other mats. Smith et al. (2000) found Piloderma mats were more common in old-growth than rotationage Douglas-fir stands, and were also associated with coarse woody debris in advanced stages of decay. Another influence of mat abundance is tree species composition. Piloderma species associate with a broad range of conifer and angiosperm tree species, but they do not form symbioses with Western Red Cedar (Thuja plicata), a prominent species in old-growth coniferous forests of the Northwestern USA. The micro-niches in which EcM mats are found could impact our comparisons of mat and non-mat soils; however, the fact that we compared neighboring mat and non-mat soils in close proximity mitigated spatial heterogeneity to some extent (for example, see how neighboring soil types cluster together in Fig. 9). The spatial distribution of Piloderma mats could also provide clues to their foraging strategy. The association between Piloderma mats and rotting wood could indicated some saprotrophic behavior in addition to utilizing carbon translocated from tree hosts (i.e. representing both heterotrophic and rhizospheric soil respiration).

\subsection{Upscaling estimates of Piloderma mat respiration}

Most experimental methods for estimating root respiration are unable to achieve reasonable physical separation of roots

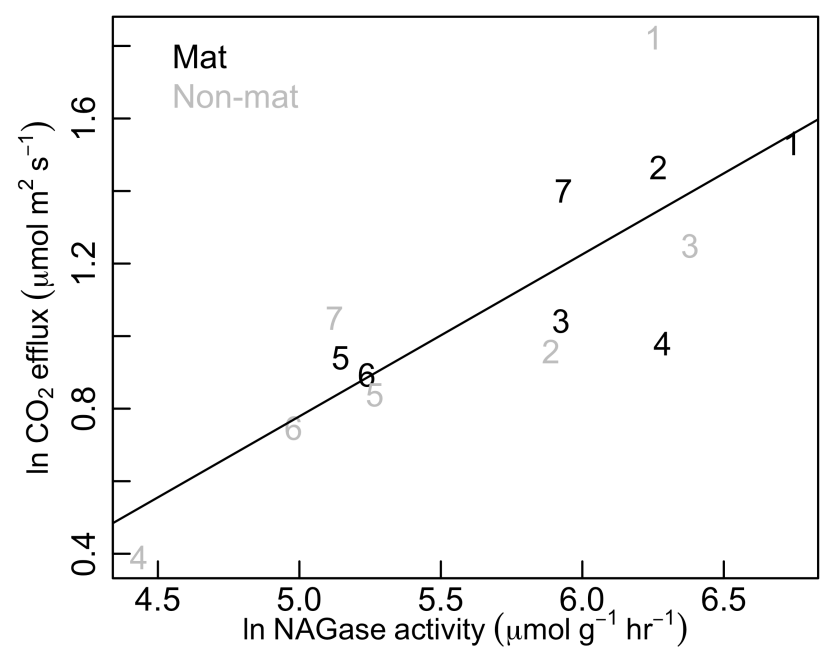

Fig. 9. Relationship between NAGase (chitinase) enzyme activity and soil surface flux. $R^{2}=0.66$. Data were analyzed with linear regression on a ln-ln basis to constrain increasing variance at higher respiration and enzyme activity levels. Black and grey colors represent mat and non-mat members of each pair, and plotted numbers indicate unique pairs.

and EcM fungal hyphae, thus their respiratory contributions are generally measured together. We compared our estimates of Piloderma mat contributions to estimates of rhizosphere respiration (root + EcM fungi) from an old-growth site less than $1 \mathrm{~km}$ from our study area and at similar elevation $\left(44^{\circ} \mathrm{N}\right.$ $14^{\prime \prime} 0^{\prime} \mathrm{N}, 122^{\circ} 13^{\prime} 0^{\prime \prime} \mathrm{W}, 531 \mathrm{~m}$ elevation), part of the Detritus Input and Removal Treatments (DIRT) experiment (Sulzman et al., 2005). Between 2001-2003, Sulzman et al. (2005) compared respiration rates from root-free trenched plots and untreated control plots, and estimated that approximately $1 / 4$ of total soil respiration came from rhizosphere respiration. If we assume similar rhizosphere contributions in the exposed forest floor of our study area and divide our estimate of Piloderma mat contributions (16\%) by total rhizosphere contributions ( $25 \%$ ), we estimate Piloderma mats may have accounted for about $40 \%$ of rhizosphere respiration in this old-growth Douglas-fir forest. It is important to note that accounting for respiration in areas of forest floor covered by downed wood and massive roots, which we did not characterize but would expect to have lower proportional mat contributions, would lower this estimate of Piloderma contributions to rhizospheric respiration. On the other hand, this $40 \%$ value likely underestimates total $\mathrm{EcM}$ fungal contributions due to the fact that non-mat forming EcM fungi were present in non-mat soils.

Previous studies have also indicated a large EcM fungal component of rhizosphere respiration. Using a mass balance approach, Fahey et al. (2005) estimated $17 \%$ of rhizosphere respiration was from mycorrhizal fungi and rhizodeposition, although the authors acknowledged this estimate had high uncertainty. Heinemeyer et al. (2007) estimated that EcM 
hyphal respiration was about $70 \%$ of rhizosphere respiration in an early seral lodgepole pine forest, at the peak occurrence of fruiting bodies. In a multi-year study in an oak system, they estimated smaller contributions, but with brief periods of high contributions when plant host activity was also high (Heinemeyer et al., 2012a). The variability among these estimates is not unlike the variability seen in estimates of total rhizosphere respiration, which varies with forest type as well as with estimation technique (Subke et al., 2006; BondLamberty et al., 2004). Despite the range in values, our results contribute to a growing consensus that EcM respiration is a substantial component of rhizosphere respiration, and indicates EcM contributions are significant both in early and late seral forests.

\subsection{Study limitations and opportunities for improvement}

We recommend EcM mats as a useful system for examining in situ the effects of EcM rhizomorphs on soil carbon cycling. Advancements in flux measurement techniques could also improve such comparisons in the future. Piloderma is a particularly abundant mat forming species in the Northwestern USA, but mat-formers in other systems could allow similar investigations of EcM mat respiration in other forest types. It is important to underscore that estimates of EcM mat respiration do not represent total mycorrhizal respiration, but they do represent a useful approach for assessing one component of mycorrhizal respiration with minimally invasive techniques.

One of the limitations of our approach was the use of soil collars, which facilitate repeated measurements but have the potential disadvantage of severing roots and hyphae in some ecosystems (Heinemeyer et al., 2011). Although our insertion depths were shallow, collarless methods would provide opportunities for improvement. Measurements with automated soil chambers would also be useful to elucidate high-frequency dynamics of mat activity, including potential relationships with photosynthetic carbon supply.

Other limitations of our approach include inherent spatial variation in mat size, density, underlying soil conditions, and microbial composition, although we attempted to overcome these limitations by quantifying subsurface processes through soil coring and vertical partitioning. Some of the advantages of mat systems were that soils were generally stable in rhizomorph density across two growing seasons and appeared to be fairly resilient to the presence of soil collars and repeated probing.

Acknowledgements. We thank Dave Myrold, Jane Smith, and Doni McKay for providing laboratory resources and intellectual guidance, and Erik Lilleskov for an insightful review. Facilities and data were provided by the H. J. Andrews Experimental Forest research program, funded by the National Science Foundation's Long-Term Ecological Research Program (DEB 08-23380), US
Forest Service Pacific Northwest Research Station, and Oregon State University. Additional funding was provided by the Northwest Scientific Association. This manuscript was completed under the auspices of the US Department of Energy, identifiedLLNL-JRNL523171.

Edited by: Z. Jia

\section{References}

Aerts, R.: The role of various types of mycorrhizal fungi in nutrient cycling and plant competition, in: Mycorrhizal Ecology, edited by: van der Heijden, M. G. A., and Sanders, I. R., Ecological Studies, Springer-Verlag, Berlin, 117-133, 2002.

Agerer, R.: Exploration types of ectomycorrhizae, Mycorrhiza, 11, 107-114, doi:10.1007/s005720100108, 2001.

Agerer, R.: Fungal relationships and structural identity of their ectomycorrhizae, Mycological Progress, 5, 67-107, doi:10.1007/s11557-006-0505-x, 2006.

Bond-Lamberty, B., Wang, C., and Gower, S. T.: A Global Relationship Between the Heterotrophic and Autotrophic Components of Soil Respiration?, Glob. Change Biol., 10, 1756-1766, 2004.

Carbone, M. S., Winston, G. C., and Trumbore, S.: Soil respiration in perennial grass and shrub ecosystems: Linking environmental controls with plant and microbial sources on seasonal and diel timescales, J. Geophys. Res., 113, G02022, doi:10.1029/2007JG000611, 2008.

Castellano, M. A.: The taxonomy of the genus Hysterangium (Basidiomycotina, Hysterangiaceae) with notes on its ecology, Ph.D., Forest Science, Oregon State University, Corvallis, OR, 238 pp., 1988.

Cromack, K., Sollins, P., Graustein, W. C., Speidel, K., Todd, A. W., Spycher, G., Li, C. Y., and Todd, R. L.: Calcium oxalate accumulation and soil weathering in mats of the hypogeous fungus Hysterangium crassum, Soil Biol. Biochem., 11, 463-468, 1979.

Davidson, E. A. and Trumbore, S. E.: Gas diffusivity and production of $\mathrm{CO}_{2}$ in deep soils of the eastern Amazon, Tellus B, 47, 550565, 1995.

Davidson, E. A., Savage, K. E., Trumbore, S. E., and Borken, W.: Vertical partitioning of $\mathrm{CO} 2$ production within a temperate forest soil, Glob. Change Biol., 12, 944-956, doi:10.1111/j.13652486.2005.01142.x, 2006.

Dixon, J. J.: Applying GIS to soil-geomorphic landscape mapping in the Lookout Creek valley, Western Cascades, Oregon, M. S., Crops and Soil Science, Oregon State University, Corvallis, 2003.

Dunham, S. M., Larsson, K.-H., and Spatafora, J. W.: Diversity and community structure of mat-forming ectomycorrhizal fungi in old growth and rotation age Douglas-fir forests fo the HJ Andrews Experimental Forest, Oregon, USA, Mycorrhiza, 17, 633645, 2007.

Erland, S. and Taylor, A.: Diveristy of ecto-mycorrhizal fungal communities in relation to the abiotic environment., in: Mycorrhizal Ecology, edited by: van der Heijden, M. G. A., and Sanders, I. R., Springer-Verlag, Berlin, 163-201, 2002.

Fahey, T., Tierney, G., Fitzhugh, R., Wilson, G., and Siccama, T.: Soil respiration and soil carbon balance in a northern hardwood forest ecosystem, Can. J. Forest Res., 35, 244-253, 2005. 
Griffiths, R. P. and Caldwell, B. A.: Mycorrhizal mat communities in forest soils, in: Mycorrhizae in ecosystems, edited by: Read, D. J., Lewis, D. H., Fitter, A. H., and Alexander, I. J., Cambridge University Press, Cambridge, 98-105, 1992.

Griffiths, R. P., Caldwell, B. A., Cromack Jr., K., and Morita, R. Y.: Douglas-fir forest soils colonized by ectomycorrhizal mats. I. Seasonal variation in nitrogen chemistry and nitrogen cycle transformation rates, Can. J. Forest Res., 20, 211-218, 1990.

Griffiths, R. P., Catellano, M. A., and Caldwell, B. A.: Hyphal mats formed by two ectomycorrhizal fungi and their association with Douglas-fir seedlings: A case study, Plant Soil, 134, 225-259, 1991.

Griffiths, R. P., Baham, J. E., and Caldwell, B. A.: Soil solution chemistry of ectomycorrhizal mats in forest soil, Soil Biol. Biochem., 26, 331-337, 1994.

Griffiths, R. P., Bradshaw, G. A., Marks, B., and Lienkaemper, G. W.: Spatial distribution of ectomycorrhizal mats in coniferous forests of the Pacific Northwest, USA, Plant Soil, 180, 147-158, 1996.

Heinemeyer, A., Hartley, I. P., Evans, S. P., Carreira de la Fuentes, J. A., and Ineson, P.: Forest soil $\mathrm{CO}_{2}$ flux: uncovering the contribution and environmental responses of ectomycorrhizas, Glob. Change Biol., 13, 1786-1797, 2007.

Heinemeyer, A., Di Bene, C., Lloyd, A. R., Tortorella, D., Baxter, R., Huntley, B., Gelsomino, A., and Ineson, P.: Soil respiration: implications of the plant-soil continuum and respiration chamber collar-insertion depth on measurement and modelling of soil $\mathrm{CO} 2$ efflux rates in three ecosystems, European J. Soil Sci., 62, 82-94, doi:10.1111/j.1365-2389.2010.01331.x, 2011.

Heinemeyer, A., Wilkinson, M., Vargas, R., Subke, J.-A., Casella, E., Morison, J. I. L., and Ineson, P.: Exploring the "overflow tap" theory: linking forest soil $\mathrm{CO}_{2}$ fluxes and individual mycorrhizosphere components to photosynthesis, Biogeosciences, 9, 79-95, doi:10.5194/bg-9-79-2012, 2012a.

Heinemeyer, A., Gruber, V., and Bahn, M.: The "Gas-Snake": Design and validation of a versatile membrane-based gas flux measurement system in a grassland soil respiration study, Agr. Forest Meteorol., 154-155, 166-173, doi:10.1016/j.agrformet.2011.10.017, 2012b.

Irvine, J., Law, B., Martin, J., and Vickers, D.: Interannual variation in soil $\mathrm{CO}_{2}$ efflux and the response of root respiration to climate and canopy gas exchange in mature ponderosa pine, Glob. Change Biol., 14, 2848-2859, 2008.

Kluber, L. A., Tinnesand, K. M., Caldwell, B. A., Dunham, S. M., Yarwood, R. R., Bottomley, P. J., and Myrold, D. D.: Ectomycorrhizal mats alter forest soil biogeochemistry, Soil Biol. Biochem., 42, 1607-1613, 2010.

Kluber, L. A., Smith, J. E., and Myrold, D. D.: Distinctive fungal and bacterial communities are associated with mats formed by ectomycorrhizal fungi, Soil Biol. Biochem., 43, 1042-1050, 2011.

Lindahl, B. D., Ihrmark, K., Boberg, J., Trumbore, S. E., Högberg, P., Stenlid, J., and Finlay, R. D.: Spatial separation of litter decomposition and mycorrhizal nitrogen uptake in a boreal forest, New Phytol., 173, 611-620, doi:10.1111/j.14698137.2006.01936.x, 2007.
Martin, J. G. and Bolstad, P. V.: Annual soil respiration in broadleaf forests of northern Wisconsin: influence of moisture and site biological, chemical, and physical characteristics, Biogeochemistry, 73, 149-182, 2005.

Miller, M., Palojarvi, A., Rangger, A., Reeslev, M., and Kjoller, A.: The Use of Fluorogenic Substrates To Measure Fungal Presence and Activity in Soil, Appl. Environ. Microbiol., 64, 613-617, 1998.

Moldrup, P., Olesen, T., Yamaguchi, T., Schjønning, P., and Rolston, D. E.: Modeling Diffusion and Reaction in Soils: Ix. the Buckingham-Burdine-Campbell Equation for Gas Diffusivity in Undisturbed Soil, Soil Sci., 164, 542-551, 1999.

Pinheiro, J. C. and Bates, D. M.: Mixed-effects models in S and S-PLUS, Springer Verlag, New York, 528 pp., 2000.

Querejeta, J. I., Egerton-Warburton, L. M., and Allen, M. F.: Direct nocturnal water transfer from oaks to their mycorrhizal symbionts during severe soil drying, Oecologia, 134, 55-64, 2003.

Risk, D., Nickerson, N., Creelman, C., McArthur, G., and Owens, J.: Forced Diffusion soil flux: A new technique for continuous monitoring of soil gas efflux, Agr. Forest Meteorol., 151, 16221631, doi:10.1016/j.agrformet.2011.06.020, 2011.

Smith, J. E., Molina, R., Huso, M., and Larsen, M. J.: Occurrence of Piloderma fallax in young, rotation-age, and old-growth stands of Douglas-fir (Pseudotsuga menziesii) in the Cascade Range of Oregon, USA, Can. J. Bot., 78, 995-1001, 2000.

Subke, J.-A., Inglima, I., and Francesca Cotrufo, M.: Trends and methodological impacts in soil $\mathrm{CO}_{2}$ efflux partitioning: A metaanalytical review, Glob. Change Biol., 12, 921-943, doi:10.1111/j.1365-2486.2006.01117.x, 2006.

Sulzman, E. W., Brant, J. B., Bowden, R. D., and Lajtha, K.: Contribution of aboveground litter, belowground litter, and rhizosphere respiration to total soil $\mathrm{CO}_{2}$ efflux in an old growth coniferous forest, Biogeochemistry, 73, 231-256, 2005.

Tang, J. and Baldocchi, D. D.: Spatial and temporal variation in soil respiration in an oak-grass savanna ecosystem in California and its partitioning into autotrophic and heterotrophic components, Biogeochemistry, 73, 183-207, 2005.

Taylor, B. N. and Kuyatt, C. E.: NIST Technical Note 1297: Guidelines for Evaluating and Expressing the Uncertainty of NIST Measurement Results, National Institute of Standards and Technology, US Dept of Commerce, Technology Administration, 1994.

Trappe, M. J., Cromack Jr, K., Caldwell, B. A., Griffiths, R. P., and Trappe, J. M.: Diversity of mat-forming fungi in relation to soil properties, disturbance and forest ecotype at Crater Lake National Park, Oregon, USA, Diversity, 4, 196-223, doi:10.3390/d4020196, 2012.

Trumbore, S. E.: Carbon respired by terrestrial ecosystems-recent progress and challenges, Glob. Change Biol., 12, 141-153, 2006.

Zeglin, L. H., Kluber, L. A., and Myrold, D. D.: The importance of amino sugar turnover to $\mathrm{C}$ and $\mathrm{N}$ cycling in organic horizons of old-growth Douglas-fir forest soils colonized by ectomycorrhizal mats, Biogeochemistry, doi:10.1007/s10533-012-9746-8, 2012. 